\title{
A!
}

This is an electronic reprint of the original article.

This reprint may differ from the original in pagination and typographic detail.

Tiismus, Hans; Kallaste, Ants; Vaimann, Toomas; Rassõlkin, Anton; Belahcen, Anouar

\section{Technologies for Additive Manufacturing of Electrical Machines}

\section{Published in:}

Proceedings of the 20th International Conference of Young Specialists on Micro/Nanotechnologies and Electron Devices, EDM 2019

DOI:

10.1109/EDM.2019.8823462

Published: 01/06/2019

Document Version

Peer reviewed version

Please cite the original version:

Tiismus, H., Kallaste, A., Vaimann, T., Rassõlkin, A., \& Belahcen, A. (2019). Technologies for Additive Manufacturing of Electrical Machines. In Proceedings of the 20th International Conference of Young Specialists on Micro/Nanotechnologies and Electron Devices, EDM 2019 (pp. 651-655). [8823462] (International Conference and Seminar of Young Specialists on Micro-Nanotechnologies and Electron Devices). IEEE. https://doi.org/10.1109/EDM.2019.8823462

This material is protected by copyright and other intellectual property rights, and duplication or sale of all or part of any of the repository collections is not permitted, except that material may be duplicated by you for your research use or educational purposes in electronic or print form. You must obtain permission for any other use. Electronic or print copies may not be offered, whether for sale or otherwise to anyone who is not an authorised user. 
(C) 2019 IEEE. This is the author's version of an article that has been published by IEEE. Personal use of this material is permitted. Permission from IEEE must be obtained for all other uses, in any current or future media, including reprinting/republishing this material for advertising or promotional purposes, creating new collective works, for resale or redistribution to servers or lists, or reuse of any copyrighted component of this work in other works. 


\title{
Technologies for Additive Manufacturing of Electrical Machines
}

\author{
Hans Tiismus ${ }^{1}$, Student Member, IEEE, Ants Kallaste ${ }^{1}$, Member IEEE, Toomas Vaimann ${ }^{1}$, Member IEEE, \\ Anton Rassõlkin ${ }^{1}$, Member IEEE, Anouar Belahcen ${ }^{1,2}$, Member IEEE \\ ${ }^{1}$ Tallinn University of Technology, Tallinn, Estonia \\ ${ }^{2}$ Aalto University, Espoo, Finland
}

\begin{abstract}
Additive manufacturing (AM) technology is considered an essential component of the Industry 4.0 revolution, due to its capability for decentralized production of highly customizable complex objects. Its design and fabrication freedom also suggest for the production capacity of goods with embedded electromechanical components and even electrical machines with enhanced performance. Currently, due to the maturity of homo-material and limited multi-material capabilities of current AM systems, prototyping of 3D printed electrical machines has taken the path of manual assembly of printed components. For fully printed end-user products containing integrated electromechanical components to emerge, evolution of the multi-material printing systems is required. This paper discusses the technical demands of additively manufacturing electrical machines and current promising technologies on the horizon to bring us one step closer to mass produced fully $3 D$ printed electrical machines.
\end{abstract}

Index Terms - Electric machines, Manufacturing processes, Magnetic materials, Three-dimensional printing

\section{INTRODUCTION}

$\mathrm{A}$ DDITIVE manufacturing or $3 \mathrm{D}$ printing is the common term for a class of technologies that produce functional components or entire assemblies from a CAD file in a layer by layer fashion. This radically different approach from subtractive methods plays a significant role in the vision of industry 4.0 by improving the capabilities of traditional manufacturing systems. Coupled with unprecedented data acquisition and analysis capacity of the Internet of Things (IoT), the fourth industrial revolution can potentially redefine the industry as we know it today, enabling for example:

- Mass personalization of goods - real-time customer feedback alongside unparalleled design and production freedom of AM allows customization of products according to individual needs and their viable smallscale production. [1]

- Decentralized production - production workload can be distributed over automated factories via utilization of cloud services. [2]

- On demand production - digital inventories will replace physical inventories when parts are produced on-demand, when actually needed. [3]

These upgrades will provide immense opportunities towards the realization of sustainable manufacturing with highly efficient resource usage, simplified logistics and individualized products. For achieving the full functionality of industry 4.0 smart factories, printing of goods containing electro-mechanical and electronic elements must be completed as a single uninterrupted process without any additional manual post-processing or assembly. This level of automated integration is not currently possible due to several limitations of the AM technology, as 3D printing of electromechanical systems is notably difficult due to high precision moving parts and multiple diverse materials involved. State of the art printing technology is currently capable of industrial level production of only homomaterial components, which could be utilized with present or novel next generation motor designs for enhancing performance.

With the AM technologies finally shifting from rapid prototyping into large scale production, the value of AM market is anticipated to jump from $\$ 9.5 \mathrm{~B}$ (2018) to $\$ 26.2 \mathrm{~B}$ (2022) worldwide [4], and the research and development of AM technologies is expected to accelerate even further - possibly unlocking industrial level multimaterial 3D printing capabilities in the near future.

\section{STATE OF THE ART OF ADDITIVELY MANUFACTURED ELECTRICAL MACHINES}

Until now, the design of EMs had mostly been limited to $2 \mathrm{D}$, mainly due to the manufacturing constraints employed by the industry. Previously, independently from the lamination industry, different motors with powder metallurgy cores have been shown to benefit from threedimensional flux paths: such as claw pole or pancake motors or designs involved in transverse flux. [5] These designs can also be realized with AM, with more refined geometries. The main advantage of AM lies in its capacity for realizing finite walls (up to $60 \mu \mathrm{m}$ ) and achieving partially hollow structures: improving motor cooling capacity, moment of inertia and material efficiency. Coupling these possibilities with the industrial level capacity of AM platforms and topology optimization capabilities of current computational systems finally have a case at pushing 3D machines into mainstream. Electrical machines can be divided into three major branches 
according to driving phenomena of their operation: electrostatic, piezoelectric (mostly for micro-electromechanical systems) ad electromagnetic motors.

3D printing capabilities have been demonstrated (Fig. 1.) for all three types of electromechanical devices [6], [7], [8], however up to date, no research team has managed to fully fabricate an electrical machine with additive manufacturing without any assembly or post-processing during or after printing. Several hybrid methods, such as component insertion during printing or assembly after printing have been devised for prototyping purposes.
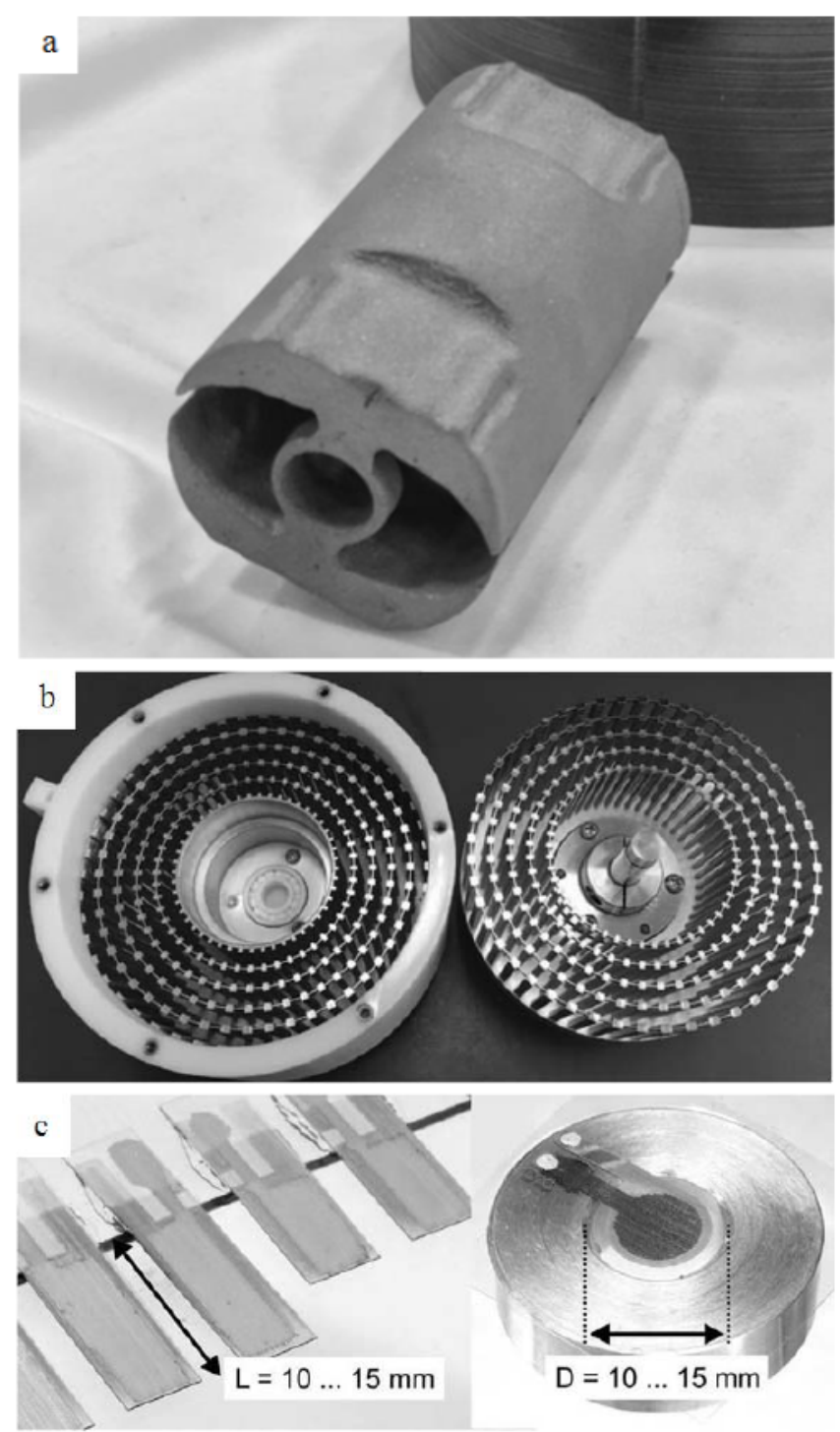

Fig. 1. (a) Selective laser melting (SLM) fabricated novel permanent magnet rotor with optimized torque density. [6] (b) Fused filament fabrication (FFF) printed rotor and stator of an electrostatic machine printed from plastic and plated with nickel. [7] (c) Inkjet printed piezoelectric actuators. [8]

Presently, due to the availability and maturity of dedicated metal printing systems, most of the research effort is concentrated on material research and rapid prototyping on these systems. However due to the limitations of these homo-material printing systems, these prototypes are manually post-processed and assembled. Nevertheless, the prototype designs pave the way for future mass-produced AMEC components and even full 3D printing of whole devices with integrated electromechanical components with the evolution of multimaterial additive manufacturing technologies in the future.

\section{DEDICATED METAL AM SYSTEMS}

Despite recent advances in polymer ferromagnetic materials [9], all ferromagnetic materials employed in electric machine industry are metallic, of which alloys of cobalt, nickel and iron are most prominently employed. Material research on $3 \mathrm{D}$ printing soft magnetic cores has also focused on these alloys. Soft ferromagnetic materials are employed in the stator and rotor construction of electrical machines for their high relative permeability and thus the ability to amplify the magnetic interactions in the EM. For minimizing core losses of the printed components, the material should also exhibit narrow hysteresis behavior and high electrical resistance.

Selective laser melting (SLM) is currently one of the oldest and most widely used AM systems for the production of functional metallic parts. It is a powder bedbased technology, which involves the selective melting of the powder with a laser in a layer-by-layer fashion. SLM has been adopted in the industry for the cost-efficient fabrication of high performance components with complex geometry. Currently state of the art selective laser melting printing system is SLM 800, with production capacity of $171 \mathrm{~cm}^{3} / \mathrm{h}$ and build envelope of $500 \times 280 \times 850 \mathrm{~mm}$. [10]

Due to the complex metallurgical phenomena involved in the miniaturized welding process of SLM, the printed material is potentially subject to various impurities and internal defects. So far, most extensive work in EM research community for optimizing the material properties for printing soft magnetic cores have been conducted by researchers from Nottingham University [6]. The authors investigated SLM printing capabilities of electrical steel with $6.9 \%$ silicone content, which is known for its excellent magnetic and electrical properties. SLM fabrication of the material however is challenging as the poor ductility and thermal conductivity are responsible for a myriad of defects generated in the printed parts. The authors achieved near fully dense crack-free parts with magnetic properties comparable to highest grade commercial materials by printing the material with optimized processing parameters and annealing the samples at high temperature. [11] Unfortunately, despite systematic optimization efforts, the same authors were unable to print a true-scale novel rotor defect free. Hot isostatic pressing (HIP) has been demonstrated in the literature for eliminating porosities and cracks formed during SLM process. The post-processing technique might prove to be the solution for improving the quality of SLM processed high silicon steel [12]. 
Binder jetting (BJ) technology is another metal powder bed-based AM technology, which instead of applying a laser for building the printed object injects a binding agent on the powder bed at room temperature. After printing process, the part is sintered at high temperature to remove a binder and consolidation of the part. Researchers from Michigan State University [5] have successfully applied this technology for printing high silicone content steel with high permeability, comparable to Somaloy magnetic composite. Due to Desktop Metal's novel production system BJ is currently in the spotlight of metal AM community. According to the company, BJ technology printing speeds is $100 \mathrm{x}$ faster than SLM quad-laser printer speed - with blazing $12,000 \mathrm{~cm}^{3} / \mathrm{hr}$, additionally minimal post-processing required. Due to absent of thermal gradient during printing and integrated heat treatment of the production process printed material is also expected exhibit lower cracking and residual thermal stresses (alongside larger grain size) [13]. Full material evaluation is yet to be conducted to verify its suitability for large scale soft magnetic core fabrication. Desktop Metal has also developed a fused deposition modelling based (FDM) Studio system for comfortable rapid prototyping of metal parts (Fig. 2.). The process involves the extrusion of a viscous paste of metallic powder and binder in layer-bylayer fashion. After printing, the printed body is sintered at high temperatures, for the removal of binder and consolidation of the part. The build envelope of the platform is $30 \times 20 \times 20 \mathrm{~cm}$ and can achieve part densities with $98 \%$ at fabrication rate of $16 \mathrm{~cm}^{3} / \mathrm{hr}$. [14]

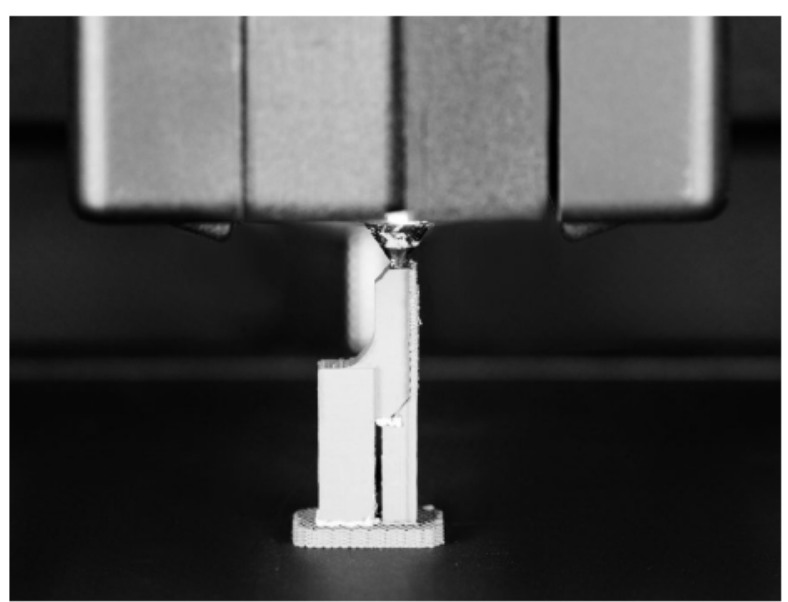

Fig. 2. Fused Deposition Modelling of a metal part with the Desktop Metal Studio System. [14]

\section{MULTI-MATERIAL PRINTING}

Currently, one of the biggest challenges in continuous printing of complete electromechanical devices is the process of coil fabrication. Electromagnetic coils are used in electro-mechanical devices for controllable magnetic field generation. Coil performance is proportional to its current density and core material used. Conductive, ferromagnetic and insulating materials typically exhibit incompatible thermal behaviours, limiting their concurrent printing and demanding hybrid printing technologies.

Presently, only extrusion-based technology has been used for successfully fabricating both core and coil components. Researchers from Singapore Technical University [15] successfully printed both soft and hard magnetic materials (Fig. 3.) with saturation magnetization values up to $95 \%$
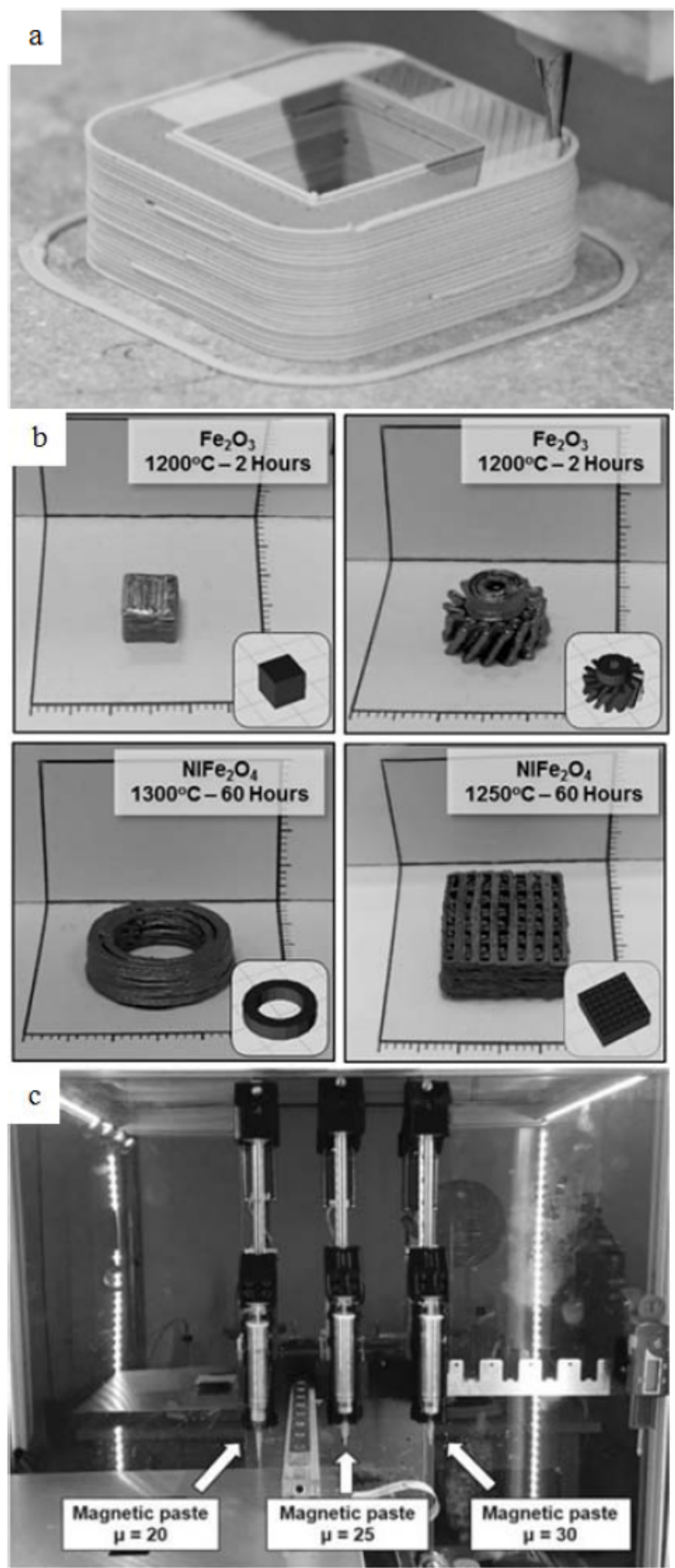

Fig. 3. (a) FDM fabrication of the world's first fully 3D printed volumetric electromagnetic coil [16], (b) Extruded ferromagnetic components after sintering, (c) Multi-extruders for printing multi-permeability parts [17] 
and densities up to $93 \%$ of the theoretical bulk values. Researchers from Chemnitz University of Technology [16] printed successfully the world's first volumetric coil with ten turns from a combination of copper and ceramics paste. The properties of the printed material were impressive: specific conductivity of $71 \%$ and density of $87 \%$ were achieved, compared to commercial grade electrolytic copper. Some authors [17] have employed a modified commercial multi-extruder paste-extrusion 3D printer for manufacturing multi-permeability magnetic cores. With the same dimensions, the 3D printed three-permeability toroid core was shown to exhibit higher inductance than a singlepermeability core.

\section{FUTURE TECHNOLOGIES}

Metals cannot be printed as means of common polymer printing methods, due to their excellent thermal conductivity. Common thermoplastic systems (ex. fused filament fabrication) feeding from a metal filament would result in partial melting of the filament and constant jams in the filament feeder system. Direct metal writing (DMW) technology, developed by researchers at Lawrence Livermore National Laboratory [18], addresses this issue and reinvents metal 3D printing. It relies extruding semisolid metals from a nozzle, whereas the material reservoir is kept in as state of shear thinning (its viscosity decreases under shear strain). This allows the control of extrusion of the material with an external force applied on the reservoir. As a proof of concept, the technology was used for successfully printing molten bismuth-tin soldering alloys with melting temperatures under $300^{\circ} \mathrm{C}$ (Fig. 4.). Currently, the DMW technology is still in its early stages and extensive work still needs to be done to achieve higher resolution, melting temperatures and industrial capabilities, however the technology seems very promising for parallel printing of both coil insulation and conductors.
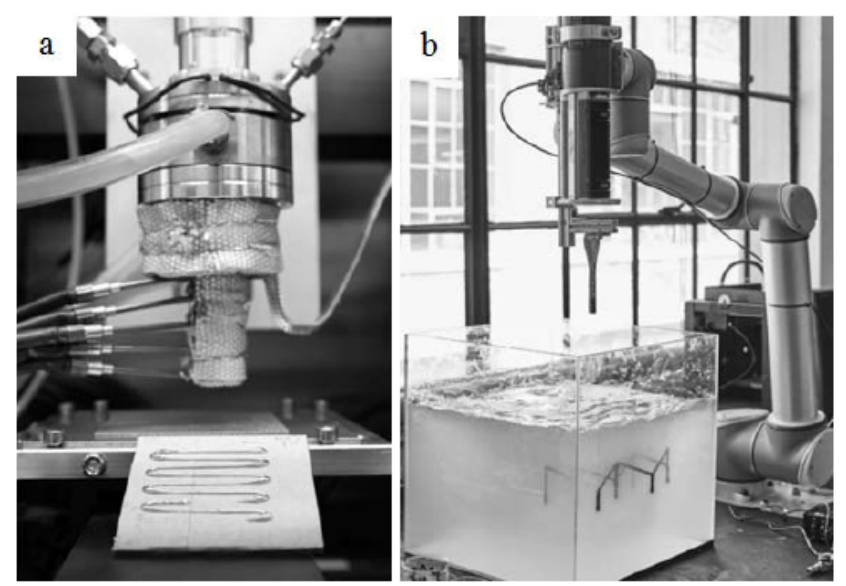

Fig.4. (a) Direct metal writing reinvents metal additive manufacturing [18], (b) Rapid Liquid Printing system [20]

The first industrial scale extrusion-based AM fabrication system is rapid liquid printing (RLP). The novel technology uses a chemically curable liquid deposition system to print into gel suspension environment. (Fig. 4.) The printing process is not affected by gravity by the virtue of viscose environment, allowing for exceptionally fast fabrication speeds. The process is scalable with gel tank and nozzle sizes and rapid enough for rivalling the furniture industry. For example, a unique shaped table top was completed 300x faster with RLP than with a traditional layer-by-layer printer. Currently MIT is experimenting with various materials for this method. Self-Assembly Lab founder, Skylar Tibbits has stated that the team has been able to use plastics, foams and even metals for RLP fabrication. [19] It can be hypotheses that with multiple printing nozzles, RLP is the industrial scale solution for multi-material extrusion printing.

\section{CONCLUSIONS}

Presently, full fabrication of an electrical machine has yet to be achieved without any assembly or post-processing during or after printing. Extrusion based additive manufacturing technologies however have been used for the printing of both the coils and ferromagnetic machine cores. As commercial FDM extrusion platforms by Desktop Metal have shown excellent performance, alongside easy and safe usage in office environment, the technology is expected to popularize 3D printing of metal parts, including prototype components for electrical machines. The technology can prove to be especially beneficial for the fabrication of alloys with poor ductility and thermal conductivity, such as high silicone steel, which struggle with SLM technology. Both DMW and RLP systems hold great prospects in 3D printing electrical machines in the future. DMW suggests capacity for printing high performance coils and RLP - rapid production capabilities of components and with possible improved multi-material capabilities in the future - printing of full electromechanical devices in mass.

\section{ACKNOWLEDGMENT}

This research work has been supported by Estonian Ministry of Education and Research (Project PSG137).

\section{REFERENCES}

[1] Y. Wang, H.-S. Ma, J.-H. Yang, and K.-S. Wang, "Industry 4.0: a way from mass customization to mass personalization production," Adv. Manuf., vol. 5.

[2] U. M. Dilberoglu, B. Gharehpapagh, U. Yaman, and M. Dolen, "The Role of Additive Manufacturing in the Era of Industry 4.0," Procedia Manuf., vol. 11, pp. 545-554, 2017.

[3] T. Stock and G. Seliger, "Opportunities of Sustainable Manufacturing in Industry 4.0," Procedia CIRP, vol. 40, no. Icc, pp. 536-541, 2016.

[4] ". 3D printing market value 2022 | Forecast." [Online]. Available https://www.statista.com/statistics/261693/3d-printing-market-valueforecast/. [Accessed: 04-Feb-2019].

[5] T. Q. Pham, T. T. Do, P. Kwon, and S. N. Foster, "Additive Manufacturing of High Performance Ferromagnetic Materials," 2018 IEEE Energy Convers. Congr. Expo., no. January 2019, pp. 43034308, 2018

[6] R. H. Michele Garibali, Ian Ashcroft, Chris Gerada, Richard Hague "Laser Additive Manufacturing of Soft Magnetic Cores for Rotating Electrical Machinery: Materials Development and Part Design." 
[7] B. Ge, D. C. Ludois, and A. N. Ghule, "A 3D Printed Fluid Filled Variable Elastance Electrostatic Machine Optimized with Conformal Mapping," 2016 IEEE Energy Convers. Congr. Expo., no. ii, pp. 1-8, 2016.

[8] G. K. Lau and M. Shrestha, "Ink-jet printing of micro-elelectromechanical systems (MEMS)," Micromachines, vol. 8, no. 6, 2017.

[9] N. A. Zaidi, S. R. Giblin, I. Terry, and A. P. Monkman, "Room temperature magnetic order in an organic magnet derived from polyaniline," Polymer (Guildf)., vol. 45, no. 16, pp. 5683-5689, 2004.

[10] "SLM 800 Metal Additive Manufacturing System for Volume Production." [Online]. Available: https://slmsolutions.us/product/slm-800/. [Accessed: 18-Feb-2019].

[11]M. Garibaldi, I. Ashcroft, J. N. Lemke, M. Simonelli, and R. Hague, "Effect of annealing on the microstructure and magnetic properties of soft magnetic Fe-Si produced via laser additive manufacturing," Scr. Mater., vol. 142, pp. 121-125, Jan. 2018.

[12]M. L. Montero-Sistiaga, M. Godino-Martinez, K. Boschmans, J.-P Kruth, J. Van Humbeeck, and K. Vanmeensel, "Microstructure evolution of 316L produced by HP-SLM (high power selective laser melting)," Addit. Manuf., vol. 23, pp. 402-410, Oct. 2018.

[13] "Home | Desktop Metal." [Online]. Available: https://www.desktopmetal.com/. [Accessed: 05-Feb-2019].

[14] "Desktop Metal Studio System for 3D printing complex metal parts in-house." [Online]. Available: https://www.javelintech.com/3d/desktop-metal-studio-system/. [Accessed: 18-Feb-2019].

[15]E. Peng, X. Wei, T. S. Herng, U. Garbe, D. Yu, and J. Ding, "Ferritebased soft and hard magnetic structures by extrusion free-forming $\dagger$," 2017.

[16]F. Lorenz, J. Rudolph, and R. Wemer, "Design of 3D Printed High Performance Windings for Switched Reluctance Machines," 2018 XIII Int. Conf. Electr. Mach., pp. 2451-2457, 2018.

[17]L. Liu et al., "Design and Additive Manufacturing of Multipermeability Magnetic Cores," IEEE Trans. Ind. Appl., vol. 54, no. 4, pp. 3541-3547, 2018.

[18]W. Chen et al., "Cite as," Appl. Phys. Lett, vol. 110, p. 94104, 2017.

[19] "3D printing is yesterday's news. Rapid liquid printing is the future WIRED UK." [Online]. Available: https://www.wired.co.uk/article/rapid-liquid-printing-mit-steelcase. [Accessed: 18-Feb-2019].

[20]"Pushing Possibilities - Steelcase." [Online]. Available https://www.steelcase.com/research/articles/topics/creativity/pushingpossibilities/. [Accessed: 18-Feb-2019].

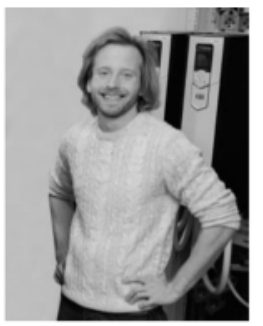

Hans Tiismus was born in 1989 in Tallinn Estonia. He received his BSc and MSc degrees in science from Tallinn University of Technology, Estonia, in 2011, 2013 respectively. $\mathrm{He}$ is currently a junior researcher and a $\mathrm{PhD}$ student in Tallinn University of Technology, Department of Electrical Power Engineering and Mechatronics.

His main research interest is the additive manufacturing of electrical machines.

E-mail: Hans.Tiismus@taltech.ee

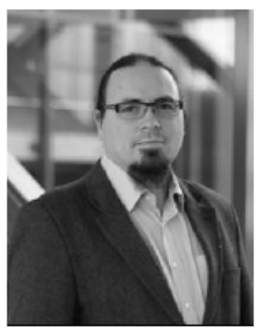

Ants Kallaste received his BSc, MSc and $\mathrm{PhD}$ degrees in electrical engineering from Tallinn University of Technology, Estonia, in 2004, 2006 and 2013 respectively. He is currently a senior researcher in Tallinn University of Technology, Department of Electrical Power Engineering and Mechatronics. He is holding the position of Head of Electrical Machines Research Group. He is the member of IEEE and Estonian Society of Moritz Hermann Jacobi. His main research interest is the design of electrical machines.

E-mail: Ants.Kallaste@taltech.ee

ORCID iD: https://orcid.org/0000-0001-6126-1878

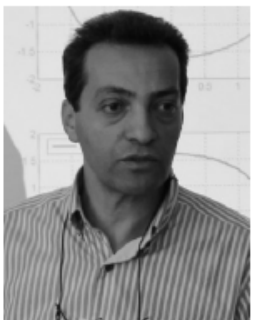

Anouar Belahcen received the BSc degree in physics from the University Sidi Mohamed Ben Abdellah Fes, Morocco, in 1988 and the MSc (Tech.) and Doctor (Tech.) degrees from Helsinki University of Technology, Finland, in 1998, and 2004 , respectively.

$\mathrm{He}$ is the professor of electrical machines at Tallinn University of Technology, Estonia and in the professor of Energy and Power at Aalto University, Finland.

His research interests are modeling of electrical machines, magnetic materials, coupled magnetic and mechanical problems, and magnetostriction.

E-mail: Anouar.Belahcen@taltech.ee

ORCID iD: https://orcid.org/0000-0003-2154-8692

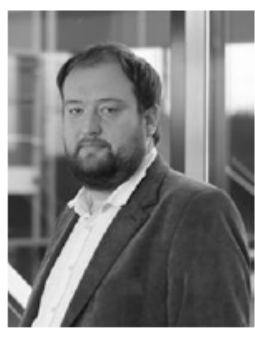

Toomas Vaimann received his BSc, MSc and $\mathrm{PhD}$ degrees in electrical engineering from Tallinn University of Technology, Estonia, in 2007,2009 and 2014 respectively. He is currently a senior researcher in Tallinn University of Technology, Department of Electrical Power Engineering and Mechatronics. $\mathrm{He}$ has been working in several companies as an electrical engineer. $\mathrm{He}$ is the member of IEEE, Estonian Society of Moritz Hermann Jacobi and Estonian Society for Electrical Power Engineering.

His main research interest is the diagnostics of electrical machines.

E-mail: Toomas.Vaimann@taltech.ee

ORCID iD: https://orcid.org/0000-0003-0481-5066

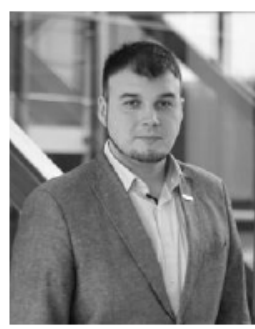

Anton Rassõlkin received the $\mathrm{Ph}$. D. degree in electric drives and power electronics from Tallinn University of Technology in 2014. He works as a Research Scientist at the Department of Electrical Power Engineering and Mechatronics at Tallinn University of Technology.

His main research interests are in the field of electric drives and their control systems as well as in the fields of electrical machines and electric transportation.

E-mail: Anton Rassolkin@taltech.ee

ORCID iD: https://orcid.org/0000-0001-8035-3970 